\title{
Socioeconomic Variables Responsible for Enhancing Non- Communicable Diseases Among Bangladeshi Adults: A Factor Analysis Approach
}

\author{
Keshab Chandra Bhuyan* \\ Former Professor of Statistics, Jahangirnagar University, Bangladesh \\ *Corresponding author: Keshab Chandra Bhuyan, Former Professor of Statistics, Jahangirnagar University, Bangladesh
}

\begin{abstract}
The present analysis was based on data collected from 785 adults investigated from families of $2 \%$ randomly selected students of American International University-Bangladesh. The students themselves collected the information from their adult family members through a pre-designed and pre-tested questionnaire. Among the investigated unit's 49.4 percent were suffering from at least one of the non-communicable diseases. Majority (85.3\%) of the NCDs affected adults were diabetic patients. The NCDs affected people were classified by their socioeconomic characters and type of disease and association between type of disease and level of some of socioeconomic characters was observed by chi-square test. Type of disease was significantly associated with residential status, age, height, occupation, income, marital status and physical labor. Among the NCDs affected people $91.2 \%$ belonged to obese and overweight group. The odd ratio indicated that the prevalence of diabetes was 1.76 times higher among obese and overweight group of respondents compared to other groups. The study of association between type of disease and level of any of the social factors did not indicate the important factor responsible for NCDs. To identify the important factors responsible for NCDs factor analysis was done. The analysis identified the variables age, followed by marital status, height, habit of taking restaurant food and occupation as responsible factors for the variation in the levels of NCDs.
\end{abstract}

Keywords: Prevalence of NCDs among adults; Socioeconomic Variables; Association of the type of NCDs and Socioeconomic Variables; Odds Ratio; Factor Analysis

\section{Introduction}

Although half of annual mortality and almost half of the burden of disease in Bangladesh are for NCDs, less evidence are available to identify the variables responsible for NCDs. The diseases which are non-infectious and non-transmissible and sometimes last for long duration even under proper medical treatment are termed as noncommunicable diseases (NCD's). The major NCDs are classified into four groups, viz.

a) Cardiovascular diseases

b) Cancer

c) Chronic respiratory diseases, and

d) Diabetes

These diseases are the major health burden in the industrialized countries and are increasing rapidly in the developing countries owing to demographic transitions and changing lifestyles among the people. The NCDs kill 41 million [1] people annually and this amount is equivalent to 71 percent of all deaths in a year. Each year 15 million die from NCDs before the age of 70 years [1-3]. More than $85 \%$ of these premature deaths from NCDs occur in low-and middle-income countries [3]. In the next decade, the death will be increased up to 24 percent [4]. Bangladesh is in the midst of an epidemiologic transition where the burden of disease is shifting from a disease profile dominated by infectious diseases, mal-nutrition and conditions of childbirth to one increasingly characterized by NCDs $[5,6]$. The NCDs were responsible for half of annual mortality (51\%) and almost half of the burden of disease (41\%) [7] Recent estimate observed in 2006 indicated that NCDs represent $68 \%$ of total death as against only $11 \%$ of total deaths due to communicable diseases [5]. The major causes of death in Bangladesh gradually shifted from acute infectious and parasitic diseases to NCDs. Diabetes is one of the major components of NCDs. It is associated with prolonged ill health and death due to vascular diseases [7-10]. Around 415 million people have diabetes in the world and 78 million people are in South-east Asia region; by 2040 
this will rise to 140 million. Bangladesh is one of the 6 countries of South-east Asia. There were 7.1 million cases of diabetes in Bangladesh in 2015.

The prevalence of diabetes in adults (20-79 years of age) was 7.4\% in Bangladesh [11]. The risk factors for cardiovascular disease are glucose and lipid abnormalities and the prevalence of this disease is a major factor due to diabetes in both developed and developing countries [12]. Diabetes is prevalent among $10 \%$ people of Bangladesh and according to the International Diabetes Federation, the prevalence will be $13 \%$ by 2030 [13]. Disease originated from tobacco smoking is another component of NCDs. It is widely used additive substance with an estimated 1.3 billion smokers worldwide and a global projected tobacco-induced death at over 6 million annually [14]. A household survey in Bangladesh estimated that tobacco-related illness was responsible for $16 \%$ of all deaths in the country [15]. It is observed from studies that some socioeconomic characteristics are responsible to enhance the diabetes and diseases related to tobacco smoking. In one study [16] it was noted that about 34 percent people of the ages 50 years and above were diabetic and prevalence of diabetes was higher among retired persons. This work was an attempt to identify socioeconomic characteristics responsible for NCDs.

\section{Methodology}

The present study was conducted in 207 randomly selected families of students of American International University Bangladesh (AIUB) during the Fall session 2015 -16. From these families 785 adults of age 18 years and above were investigated. The data were collected by the selected students through pre-designed and pretested printed questionnaire. Among the respondents, 388 (49.4\%) were suffering from at least one of the non-communicable diseases. The questionnaire contained questions related to sociodemographic characteristics of each person. It also contained questions related to type of disease, duration of suffering from the disease and information related to treatment. Some of the variables were qualitative in nature. For analytical purpose, all the variables were measured in nominal scores. In some studies, it was mentioned that Body Mass Index [BMI = Weight (in kg) / Height (in $\left.\left.\mathrm{cm}^{2}\right)\right]$ and obesity was associated with NCDs $[10,17,18]$. Accordingly, attempt was made to relate BMI with NCDs. The association of prevalence of NCDs with other social characters was studied by chi-square test. Association of BMI and diabetes were also studied here. Factor analysis was performed to identify the socioeconomic variables responsible for the NCD affected adults. The data was analyzed using SPSS version 25.

\section{Results}

Table 1: Distribution of respondents by prevalence of NCDs and some social factors.

\begin{tabular}{|c|c|c|c|c|c|c|}
\hline \multirow{3}{*}{$\begin{array}{c}\text { Social Factors } \\
\text { Residence }\end{array}$} & \multicolumn{4}{|c|}{ Prevalence of NCDs } & \multirow{2}{*}{\multicolumn{2}{|c|}{ Total }} \\
\hline & \multicolumn{2}{|c|}{ Yes } & \multicolumn{2}{|c|}{ No } & & \\
\hline & $\mathbf{n}$ & $\%$ & $\mathbf{n}$ & $\%$ & n & $\%$ \\
\hline Rural & 63 & 60.0 & 42 & 40.0 & 105 & 13.4 \\
\hline Urban & 325 & 47.8 & 355 & 52.2 & 680 & 86.6 \\
\hline Total & 388 & 49.4 & 397 & 50.6 & 785 & 100.0 \\
\hline \multicolumn{7}{|c|}{ Gender } \\
\hline Male & 255 & 47.2 & 285 & 52.8 & 540 & 68.8 \\
\hline Female & 133 & 54.3 & 112 & 45.7 & 245 & 31.2 \\
\hline Total & 388 & 49.4 & 245 & 50.6 & 785 & 100.0 \\
\hline \multicolumn{7}{|c|}{ Marital Status } \\
\hline Married & 233 & 60.2 & 154 & 39.8 & 387 & 49.3 \\
\hline Unmarried & 146 & 38.0 & 238 & 62.0 & 384 & 48.9 \\
\hline Widow \& Divorced & 9 & 64.3 & 5 & 30.8 & 14 & 1.8 \\
\hline Total & 388 & 49.4 & 397 & 50.6 & 785 & 100.0 \\
\hline \multicolumn{7}{|c|}{ Level of BMI } \\
\hline$<20$ & 6 & 23.1 & 20 & 76.9 & 26 & 3.3 \\
\hline $20-25$ & 28 & 34.6 & 53 & 65.4 & 81 & 10.3 \\
\hline $25-30$ & 191 & 48.0 & 207 & 52.0 & 398 & 50.7 \\
\hline $30^{+}$ & 163 & 58.2 & 17 & 41.8 & 280 & 5.7 \\
\hline Total & 388 & 49.4 & 397 & 50.6 & 785 & 100.0 \\
\hline
\end{tabular}

Among 785 respondents 388 (49.4\%) were suffering from at least one of NCDs. The investigated units were classified by prevalence of NCDs and some of the social characters. The classification was also done by the presence of NCD and by the levels of BMI. The classified results were used to test the independence of any two characters. As shown in Table 1, 86.6\% respondents were from urban area and among them the prevalence rate of NCDs was $47.8 \%$ against the overall prevalence rate 49.4 among all 
respondents. The differentials in prevalence of NCDs and residence were significant $\left[\chi^{\wedge} 2=5.421, p\right.$-value is 0.02$]$. The odds ratio (1.64) $[19,20]$ indicated that the urban people had 0.64 times more chance than the rural people to be affected by NCD. Among the respondents $68.8 \%$ were males and $47.2 \%$ of them were suffering from NCDs.
The percentage of female respondents (54.3) who were suffering from NCDs was more. However, the differentials in proportions of male and female patients of NCDs were not statistically. Statistically significant [ $\chi^{\wedge} 2=3.364, \mathrm{p}$-value is 0.067$]$. The males were less exposed [odds ratio $=0.75$ ] to NCD compared to females.

Table 2: Distribution of respondents by type of NCDs and some socioeconomic factors.

\begin{tabular}{|c|c|c|c|c|c|c|c|c|c|c|}
\hline \multirow{3}{*}{ Socioeconomic Factors } & \multicolumn{8}{|c|}{ Type of NCDs } & \multirow{2}{*}{\multicolumn{2}{|c|}{ Total }} \\
\hline & \multicolumn{2}{|c|}{ Diabetes } & \multicolumn{2}{|c|}{ Heart problem } & \multicolumn{2}{|c|}{ Diabetes \&heart } & \multicolumn{2}{|c|}{ Others } & & \\
\hline & $\mathrm{n}$ & $\%$ & $\mathrm{n}$ & $\%$ & $\mathrm{n}$ & $\%$ & $\mathrm{n}$ & $\%$ & $\mathrm{~N}$ & $\%$ \\
\hline Rural & 46 & 73.0 & 10 & 15.9 & 5 & 7.9 & 2 & 3.2 & 63 & 16.2 \\
\hline Urban & 285 & 87.7 & 24 & 7.4 & 9 & 2.8 & 7 & 2.1 & 325 & 83.8 \\
\hline Total & 331 & 85.3 & 34 & 8.8 & 14 & 3.6 & 9 & 2.3 & 388 & 100 \\
\hline \multicolumn{11}{|c|}{ Gender } \\
\hline Male & 223 & 87.4 & 22 & 8.6 & 5 & 2 & 5 & 2.0 & 255 & 65.7 \\
\hline Female & 108 & 81.2 & 12 & 9 & 9 & 6.8 & 4 & 3.0 & 133 & 34.3 \\
\hline Total & 331 & 85.3 & 34 & 8.8 & 14 & 3.6 & 9 & 2.3 & 388 & 100.0 \\
\hline \multicolumn{11}{|c|}{ Marital Status } \\
\hline Married & 185 & 79.4 & 30 & 12.9 & 11 & 1.7 & 7 & 3.0 & 233 & 60.1 \\
\hline Unmarried & 141 & 96.5 & 2 & 1.4 & 1 & 0.7 & 2 & 1.4 & 146 & 37.6 \\
\hline Widow \& Divorced & 5 & 55.6 & 2 & 22.2 & 2 & 22.2 & - & - & 9 & 2.3 \\
\hline Total & 331 & 85.3 & 34 & 8.8 & 14 & 3.6 & 9 & 2.3 & 388 & 100 \\
\hline \multicolumn{11}{|c|}{ Religion } \\
\hline Muslim & 294 & 85.2 & 30 & 8.7 & 12 & 3.5 & 9 & 2.6 & 345 & 88.9 \\
\hline Hindu & 34 & 85 & 4 & 10 & 2 & 5.0 & - & - & 40 & 10.3 \\
\hline Others & 3 & 100.0 & - & - & - & - & - & - & 3 & 0.8 \\
\hline Total & 331 & 85.3 & 34 & 88 & 14 & 3.6 & 9 & 2.3 & 388 & 100.0 \\
\hline \multicolumn{11}{|c|}{ Age groups (in years) } \\
\hline$<20$ & 15 & 100.0 & - & - & - & - & - & - & 15 & 3.9 \\
\hline $20-25$ & 122 & 98.4 & 1 & 0.8 & - & - & 1 & 0.8 & 124 & 32 \\
\hline $25-30$ & 15 & 83.3 & 2 & 11.1 & 1 & 5.6 & - & - & 18 & 4.6 \\
\hline $30-45$ & 50 & 78.1 & 11 & 17.2 & 2 & 3.1 & 1 & 1.6 & 64 & 16.5 \\
\hline $45+$ & 129 & 77.2 & 20 & 12 & 11 & 6.6 & 7 & 4.2 & 167 & 43.0 \\
\hline Total & 331 & 85.3 & 34 & 8.8 & 14 & 3.6 & 9 & 2.3 & 388 & 100.0 \\
\hline \multicolumn{11}{|c|}{ Level of Education } \\
\hline Illiterate & 11 & 73.3 & 3 & 20.0 & 1 & 6.7 & - & - & 15 & 3.9 \\
\hline Primary & 29 & 87.9 & 2 & 6.1 & 1 & 3.0 & 1 & 3.0 & 33 & 8.5 \\
\hline Secondary & 49 & 75.4 & 8 & 12.3 & 5 & 7.7 & 3 & 4.6 & 65 & 16.8 \\
\hline Graduate & 196 & 90.7 & 14 & 6.5 & 3 & 1.4 & 3 & 1.4 & 216 & 55.7 \\
\hline Post - graduate & 46 & 78.0 & 7 & 11.9 & 4 & 6.8 & 2 & 3.4 & 59 & 15.2 \\
\hline Total & 331 & 85.3 & 34 & 8.8 & 14 & 3.6 & 9 & 2.3 & 388 & 100.0 \\
\hline \multicolumn{11}{|c|}{ Occupation } \\
\hline Agriculture & 6 & 75.0 & 2 & 25.0 & -- & & - & - & 8 & 2.1 \\
\hline Business & 33 & 75.0 & 9 & 20.5 & 2 & 4.5 & - & - & 44 & 11.3 \\
\hline Service & 69 & 84.1 & 8 & 9.8 & 3 & 3.7 & 2 & 2.4 & 82 & 21.1 \\
\hline Retired & 15 & 60.0 & 5 & 20.0 & 3 & 12.0 & 2 & 8.0 & 25 & 6.4 \\
\hline Housewife & 60 & 78.9 & 7 & 9.2 & 5 & 6.6 & 4 & 5.3 & 76 & 19.6 \\
\hline Students & 140 & 98.6 & 1 & 0.7 & - & - & 1 & 0.7 & 142 & 36.6 \\
\hline Others & 8 & 72.7 & 2 & 18.2 & 1 & 9.1 & - & - & 11 & 2.8 \\
\hline
\end{tabular}




\begin{tabular}{|c|c|c|c|c|c|c|c|c|c|c|}
\hline Total & 331 & 85.3 & 34 & 8.8 & 14 & 3.6 & 9 & 2.3 & 388 & 100.0 \\
\hline \multicolumn{11}{|c|}{ Monthly Family Income (in Thousands) } \\
\hline$<10$ & 23 & 76.7 & 4 & 13.3 & 2 & 6.7 & 1 & 3.3 & 30 & 7.7 \\
\hline $10-20$ & 30 & 81.1 & 4 & 10.8 & 3 & 8.1 & - & - & 37 & 9.5 \\
\hline $20-30$ & 23 & 85.2 & 3 & 11.1 & 1 & 3.7 & - & - & 27 & 7.0 \\
\hline $30-40$ & 21 & 67.7 & 6 & 14.4 & 2 & 6.5 & 2 & 6.5 & 31 & 8.0 \\
\hline $40-50$ & 20 & 74.1 & 7 & 25.9 & - & - & - & - & 27 & 7.0 \\
\hline $60+$ & 28 & 77.8 & 5 & 13.9 & 2 & 5.5 & 1 & 2.8 & 36 & 9.3 \\
\hline No income & 186 & 93.0 & 5 & 2.5 & 4 & 2.0 & 5 & 2.5 & 200 & 51.5 \\
\hline Total & 331 & 85.3 & 34 & 8.8 & 14 & 3.6 & 9 & 2.3 & 388 & 100.0 \\
\hline \multicolumn{11}{|c|}{ Smoking Habit } \\
\hline Yes & 47 & 77.0 & 10 & 16.4 & 3 & 4.9 & 1 & 1.6 & 61 & 15.7 \\
\hline No & 278 & 86.9 & 23 & 7.2 & 11 & 3.4 & 8 & 2.5 & 320 & 82.5 \\
\hline Not Applicable & 6 & 85.7 & 1 & 14.3 & - & - & - & - & 7 & 1.8 \\
\hline Total & 311 & 85.3 & 34 & 8.8 & 143.6 & & 9 & 2.3 & 388 & 100.0 \\
\hline \multicolumn{11}{|c|}{ Physical Labor } \\
\hline Yes & 155 & 79.9 & 25 & 12.9 & 8 & 4.1 & 6 & 3.2 & 194 & 50.0 \\
\hline No & 176 & 90.7 & 9 & 4.6 & 6 & 3.1 & 3 & 1.5 & 194 & 50.0 \\
\hline Total & 331 & 85.3 & 34 & 8.8 & 14 & 3.6 & 9 & 2.3 & 388 & 100.0 \\
\hline \multicolumn{11}{|c|}{ Habit of Taking Processed Food } \\
\hline Yes & 161 & 84.3 & 17 & 8.9 & 10 & 5.2 & 7 & 3 & 424 & 54 \\
\hline No & 170 & 86.3 & 17 & 8.6 & 4 & 2.0 & 2 & 1.4 & 361 & 46 \\
\hline Total & 331 & 85.3 & 34 & 8.8 & 14 & 3.6 & 9 & 2.3 & 785 & 100.0 \\
\hline \multicolumn{11}{|c|}{ Age (in years) } \\
\hline$<20$ & 6 & 100.0 & - & - & - & - & - & - & 6 & 1.5 \\
\hline $20-25$ & 27 & 96.4 & 1 & 3.6 & - & - & - & - & 28 & 7.2 \\
\hline $25-30$ & 166 & 86.9 & 16 & 8.4 & 4 & 2.1 & 5 & 2.6 & 191 & 49.2 \\
\hline $30+$ & 132 & 81.0 & 17 & 10.4 & 10 & 6.1 & 4 & 2.4 & 163 & 42.1 \\
\hline Total & 331 & 85.3 & 34 & 8.8 & 14 & 3.6 & 9 & 2.3 & 388 & 100.0 \\
\hline
\end{tabular}

Among the respondents $49.3 \%$ were married. The prevalence rate of NCDs among them was $60.2 \%$. The prevalence rate was also higher among widow and divorced respondents. The differentials in prevalence rate by marital status of the respondents were significant $\left[\chi^{\wedge} 2=40.994\right.$, $p$-value was 0.000$]$. The married persons had more chance to be affected by NCDs compared to single person [odds ratio $=2.37$ ]. The respondents were classified by their level of BMI and it was observed that 35.7 percent respondents were obese and among the obese group 58. 2 percent were affected by NCDs. Upward trend was observed in the proportions of NCDs with the increase in levels of BMI. Similar result was also observed in other studies $[10,16,18]$. Significant association was observed between prevalence of NCDs and level of BMI [= 23.355, p-value $=0.000]$. However, the odds ratio $[0 . R=0.83]$ did not indicate that obese people would be more exposed to NCDs. So far, we presented the analytical results (Table 1) to study the prevalence of NCDs among the respondents and found that prevalence of NCDs was associated with some social factors. So, we need to identify those social factors which were responsible for the prevalence of types of NCDs. This was done by factor analysis [21]. Before that, let us investigate the association of important social factors with different types of NCDs. From the study, it was noted that diabetic was the main component of NCDs as 85.3 percent of the NCDs affected people were diabetic (Table 2) and 86.1 percent of them were from urban residence. Seventy three percent rural people were diabetic, and they were less exposed to diabetes [O.R. $=0.40]$ compared to urban people. The types of NCDs and residence of respondents were significantly associated $\left[\chi^{2}=11.447, \mathrm{p}\right.$-value $=$ 0.043]. Among the NCDs affected people 65.7 per cent were male and 87.5 percent of them were diabetic. The corresponding figure among female was 81.2. However, the differentials in proportions of diabetic male and diabetic female patients were statistically similar [ $\chi^{2}=7.411, \mathrm{p}$-value $\left.=0.192\right]$. However, male respondents were 61 percent more exposed to diabetes than their female counterparts [0. R=1.61] study [22] where association of prevalence of NCDs and age was studied. Majority (39\%). The differentials in proportions of different types of patients of different ages were significantly differen $\left[\chi^{2}=37.121, p-\right.$ value $=0.011$. $]$. Similar findings were noted in a separate study [10]. Among NCDs affected respondent's 60.1 percent were married and 79.4 percent of them were diabetic. More than 96 percent unmarried NCDs affected people were diabetic. The proportions of different types of NCDs among the respondents 
of different types of marital statuses were significantly different as [ $\chi^{2}=34.632, \mathrm{p}-$ value $=0.000$. But they were similarly exposed to diabetes as O.R. $=0.38$.

From the point of religion, no group could be identified as worse suffer from diabetes. Proportions of different types of NCDs were similar for both religious groups [ $\chi^{2}=1.872$, p-value $\left.=0.997\right]$. But Muslims were more exposed to diabetes as $0 . R .=1.53$. Most (98.4\%) of the NCDs affected people who were in the age group 20 - 25 years were diabetic. All the youngest respondents $(100 \%$, $<20$ years) were diabetic. Those who were 45 years and above by age lower proportion of them were diabetic (77.2 \%). But among the diabetic patients they were around 40 percent. The proportions of NCDs affected people were in increasing trend, except the higher educated, people, with the increase in level of education. But the differentials in proportions due to a different type of NCDs and different levels of education were not significant $\left[\chi^{2}=28.772\right.$, $\mathrm{p}$-value $=0.092]$. All were similarly exposed to diabetes. This could be concluded from the result of O.R $=0.55$ in favor of higher educated diabetic patients. Majority of the NCDs affected persons were students $(36.6 \%)$ followed by servicemen. Out of 142 students of this category 140 were diabetic. Among 21.1 percent NCDs affected servicemen 84.1 percent were diabetic. Different proportions calculated for types of NCDs among different professionals were not similar $\left[\chi^{2}=71.934, \mathrm{p}\right.$ - value $\left.=0.000\right]$. Significant association of occupation and prevalence of NCDs was observed in a separate study [20]. Majority (51.5\%) of the NCDs affected people had monthly income 60 thousand and above and 93 percent of them were suffering from diabetes. This percentage was highest among all the diabetic patients having different levels of income. Levels of income and types of NCDs were significantly associated as was observed by chi-square test $\left[\chi^{2}=53.029, \mathrm{p}\right.$ - value $\left.=0.006\right]$.

Among the NCDs affected patient's 15.7 percent were smokers and 77 percent of them were diabetic. Around 87 percent nonsmokers were also diabetic. However, there was no significant difference between smoking habit and types of NCDs $\chi^{2}=7.101$, $\mathrm{p}$ - value $=0.716$. Half of the NCDs affected people were involved in physical labor and 79.9 percent of them were diabetic. As was expected, 90.7 percent of another 50 percent were diabetic. The proportion of diabetic patients among people without any physical labor was significantly different than the people who were doing some sort of physical labor $\left[\chi^{2}=12.814, \mathrm{p}-\right.$ value $=0.025$.]. Physical labor had a significant negative impact on diabetes [20]. The people involved in physical labor were less exposed to diabetes. This was noted from the result of O.R. $=0.86$. Almost half (49.2\%) of the NCDs affected people were habituated in taking canned or processed food. However, habit of taking canned food did not influence the prevalence of diabetes [ $\chi^{2}=5.725, \mathrm{p}-$ value $\left.=0.334\right]$. Level of BMI and hence the level of obesity is an enhancing factor of diabetes $[10,16-18]$. This is true if we consider the prevalence of diabetes among the adults or even among the children and adolescents [22]. But the present study did not support this fact because level of BMI was independent of level of NCDs [ $\chi^{2}=10.823, p-$ value $\left.=0.765\right]$. It had happened as 85.3 percent NCDs affected people were diabetic irrespective of level of BMI.

\section{Factor Analysis}

Table 3: Results of Factor analysis.

\begin{tabular}{|c|c|c|c|c|c|c|c|}
\hline \multirow{2}{*}{ Variables } & \multicolumn{3}{|c|}{ Coefficients of Factors } & \multicolumn{2}{c|}{ Communality } \\
\cline { 2 - 8 } & $\mathbf{F}_{1}$ & $\mathbf{F}_{2}$ & $\mathbf{F}_{3}$ & $\mathbf{F}_{4}$ & $\mathbf{F}_{5}$ & $\mathbf{F}_{\mathbf{6}}$ & $\mathbf{F}_{7}$ \\
\hline Residence & 0.271 & -0.175 & -0.01 & 0.543 & -0.378 & 0.205 & 0.585 \\
\hline Age & -0.705 & 0.236 & 0.057 & 0.354 & 0.194 & -0.147 & 0.741 \\
\hline Gender & -0.406 & 0.617 & -0.121 & 0.275 & -0.043 & -0.12 & 0.715 \\
\hline Weight & 0.281 & -0.544 & 0.287 & 0.203 & 0.268 & -0.053 & 0.573 \\
\hline Height & 0.506 & -0.519 & 0.287 & -0.043 & 0.047 & -0.256 & 0.673 \\
\hline Marital Status & 0.7 & 0.296 & 0.28 & -0.316 & -0.114 & 0.163 & 0.742 \\
\hline Religion & -0.191 & -0.336 & 0.157 & -0.032 & -0.351 & -0.257 & 0.396 \\
\hline Education & 0.44 & -0.392 & 0.238 & 0.401 & -0.223 & -0.037 & 0.559 \\
\hline Occupation & 0.485 & 0.687 & 0.013 & 0.016 & -0.029 & 0.006 & 0.761 \\
\hline Income & 0.427 & 0.434 & 0.229 & 0.354 & 0.092 & -0.124 & 0.607 \\
\hline Family size & 0.031 & 0.119 & 0.298 & -0.044 & 0.652 & -0.275 & 0.693 \\
\hline Food habit & 0.091 & -0.022 & -0.343 & 0.331 & 0.289 & 0.512 & 0.514 \\
\hline Restaurant food & -0.491 & 0.037 & 0.253 & 0.065 & 0.031 & 0.299 & 0.685 \\
\hline Processed food & -0.201 & -0.046 & 0.575 & -0.035 & -0.066 & 0.547 & $0 / 679$ \\
\hline Physical labor & 0.325 & 0.038 & 0.589 & 0.331 & 0.431 & 0.077 & 0.526 \\
\hline Smoking habit & -0.08 & 0.409 & 0.418 & 0.413 & -0.263 & -0.32 & 0.58 \\
\hline
\end{tabular}


It had already been noted that prevalence of NCDs was significantly associated with many socioeconomic variables. But all variables were not similarly influencing in enhancing the level of NCDs. Some were more important than others to enhance the types of NCDs. The most important factors for the variation in the data set can generally be identified by factor analysis, where higher factor loading indicates the more responsible factor for the variation. During factor analysis one result called communality is found out for all variables used in factor analysis. Higher the communality of a variable, higher capacity of the extracted factors to explain the variability in the data set. Again, communality is the sum of squares of the factor loadings. Hence, higher loading of a factor indicates the more importance of a variable to explain the variation in the data set [21]. In the present analysis we did the factor analysis and the results were presented in Table 3. The extracted factors could explain maximum variation of the variable occupation as its communality was higher $(0.761)$ followed by marital status, age and gender. The analysis could explain 62.67 percent variation of the data set by the extracted factors. The coefficients of the first factor indicated that age of the respondent followed by marital status was very important to study the change in the levels of NCDs. Height and occupation of the person were also influencing factors in changing the levels of NCDs.

\section{Discussion}

The study was based on data collected from 785 adult respondents from 207 randomly selected families of the students of American International University- Bangladesh. Among the respondents 388 were suffering from at least one of the noncommunicable diseases. Among this group $85.3 \%$ were exclusively suffering from diabetes. Similar higher rate of diabetic group among NCDs affected people were also observed in other studies [7-10]. The other diseases were heart problem (8.8\%), heart and diabetes (3.6\%) and only 2.3 percent respondents were suffering from other diseases. Among the diabetic patients $39.9 \%$ respondents were obese as against 5.7 percent obese in the sample. The different diseases were significantly associated with residence, marital status, age, height, education, occupation, income, physical labor. Factor analysis also supported this fact. The association was studied by $\chi^{\wedge} 2$ test. The prevalence rate of NCDs among urban people was $47.8 \%$. But this rate was higher $(60 \%)$ among the rural people. The prevalence of NCDs was observed higher (60.2\%) among the married respondents. Among the NCDs affected patient's 43 percent were of the age group 45 years and above and 77.2 percent of them were suffering from diabetes. Major NCDs exposed respondents were diabetic and among the diabetic patient's 40 percent were of age group 45 years and above. This finding is similar to that observed in home and abroad $[17,18,20]$. Among the NCDs affected persons 70.4 percent were at least graduate and 88 percent of them were diabetic; 36.6 percent were student and 98.6 percent of them were diabetic. The next higher percentage was observed among servicemen and retired persons and 78.5 percent of this latter group were diabetic. The next big group of NCDs affected persons were housewives and 78.9 percent of them were diabetic. More than 51 percent NCDs affected people had income 60 thousand and above and 93 percent of them were diabetic. Majority (90.7\%) of the NCDs affected people who did not do any physical labor were diabetic. Disease and physical labor were significantly associated. Obesity is one of the risk factors of prevalence of NCDs and it enhances arterial hypertension, diabetes, renal failure etc. [16]. In this study also it was observed that 91.2 percent NCDs affected people were overweight and obese and 84.2 percent of them were diabetic. From the factor analysis it was noted that age, height, occupation, marital status were the most important variables for the prevalence of NCDs. Similar findings were observed in both home and abroad $[1,5,6,17,18]$.

\section{Conclusion}

Non-communicable diseases are the leading cause of death in low-and middle-income countries [3]. The key diseases of NCDs are cancer, cardiovascular diseases, Chronic Kidney Diseases [CKD]. But CKD is a contributing factor to the incidence and outcomes of at least three of the diseases targeted by WHO [3]. These three are diabetes, hypertension, and cardiovascular diseases. In a separate study, it was noted that most of the Bangladeshi urban adults [13] were suffering from diabetes (36.3\%). Very few (3.1\%) were suffering from heart disease and from hypertension $(0.6 \%)$. The prevalence of diabetes in adults (20-79 years of ages) was 7.4 per cent in Bangladesh [13]. The disease cannot be avoided but it needs to be controlled. Therefore, action plan should be formulated to encourage the people so that they can avoid those factors which are responsible for NCDs. WHO [3] identified the factors responsible for NCDs and diabetes at the national level? In this study, attempt was made to identify the most responsible factor(s) for NCDs among 785 selected adults of ages 18 years and above. Among these adults, 49.4 percent were affected by at least one of the NCDs. In separate studies $[10,14,16,18]$, it was reported that age, occupation, marital status, food habit, residence and income were the responsible factors for NCDs. In this study also, the similar phenomena was noted. Rural people, currently married adults, adults of higher income and of ages 45 and above were more exposed to NCDs. Factor analysis indicated that the most responsible factor for risk of prevalence of NCDs was age followed by marital status, height, habit of taking restaurant food and occupation.

NCDs are the major health burden in both developed and developing countries. The incidence of NCDs cannot be avoided, but its prevalence can be reduced by implementing appropriate action plan. The following actions are very important to reduce the prevalence rate. These are

a) Halt the rise in level of BMI by encouraging people to participate in blood screening programs and to encourage them to do some sorts of physical labor / physical exercise.

b) Motivation campaign is to be conducted to control level of blood sugar by taking healthy food and avoiding those food which are injurious to health.

c) Motivation campaign is to be conducted to reduce tobacco 
consumption by informing the people about the health hazard of tobacco consumption.

d) To motivate eligible people to join counseling campaign for drug therapy so that heart attacks can be reduced.

e) To take action for availability of affordable basic technologies and essential medicines to treat major non-communicable diseases.

f) Motivation campaign is to be conducted to inform the people to consult the health worker / doctor before complexity arises with health condition.

The public health authority can play a decisive role for the above steps.

\section{References}

1. WHO (2013) Global action plan for the prevention and control of NCDs 2013-2020.

2. Omran AR (1971) The epidemiological transition: a theory of the epidemiology of population change. Milbank Q 83(4): 731-757.

3. WHO (2018) Fact sheets.

4. WHO (2005) Preventing chronic diseases a vital investment cataloguing

5. Karar ZA, Alam N, Streatfield PK (2009) Epidemiological transition in rural Bangladesh. Global Health Action 19: 1904.

6. Bangladesh Bureau of Statistics (2007) Statistical Pocket Book of Bangladesh.

7. WHO (2004) Death and Daily estimates for 2002 by Cause for WHO member states. Word Health Organization, Geneva, Switzerland.

8. Lozano R, Naghvi M, Foreman K, Lim S, Shibuya K, et al. (2012) Global and regional mortality from 235 causes of death for 20 age groups in 1990 and 2010: a systematic analysis for the global burden of disease study 2010. Lancet 380(9859): 2095-2128.

9. Murray CJL, VOST, Lozazo R, Naghavi M, Flaxman AD, et al. (2012) Disability adjusted life years for 291 disease and injuries in 21 regions, 1990-2010: a systematic analysis for the global burden of disease study 2010, Lancet 380(9859): 2197-2223.
10. Bhuyan KC, Fardus J, Rahman S (2016) Relationship between socioeconomic factors and diabetes among urban and rural people of Bangladesh: A Factor Analysis Approach. Global Journal of Quantitative Science 3(4): 14-21.

11. Silink M, Tuomilehto J (2011) Prevention and control of diabetes with a focus on low- and middle-income countries, paper 6, A prioritized research agenda for prevention and control of non-communicable diseases, WHO, Geneva, Switzerland.

12. Prakashchandra RD, Naido DP, Glycaemic (2016) Control profile in diabetic patients: A sub-analysis of the phoenix lifestyle project. Euromediterranean Biomedical Journal 11(5): 33-39.

13. International Diabetes Federation (IDF), Diabetes atlas $\left(6^{\text {th }}\right.$ edn.); Country estimates table 2011, The International Diabetes Federation, Belgium.

14. Bhuyan KC, Fardus J, Khanam M (2016) Discriminating the students of universities by their smoking habit. AJSE 15(1): 1-10.

15. WHO (2007) Impact of tobacco-related illness in Bangladesh. World Health Organization, Bangladesh.

16. Jannatul F, Bhuyan KC (2016) Discriminating diabetic patients of some rural and urban areas of Bangladesh: A discriminant analysis approach. EMBJ 11(19): 134-140.

17. Calamusa G, Amodio E, Costantino C, Maria Di Pasquale, Vivana Gelsomino, et al. (2012) Body mass index and factors associated with overweight and obesity; A cross-sectional study of adult subjects living in a small city of Western Sicily (Italy). Italian Journal of Public Health 9(3): 7539-7599.

18. Akter S, Rahaman MM, Sarah Krull Abe, Sultana S (2014) Prevalence of diabetes and their risk factors among Bangladeshi adults: a nationwide survey. WHO 92: 204-213.

19. Altman DG (1991) Practical Statistics for Medical Research, Chapman and Hall, London. 10(10): 1635-1636.

20. Sudeep S Silent killer (2012) Economic opportunity: Rethinking noncommunicable disease, Centre on Global Health Security, World Bank, USA.

21. Bhuyan KC (2005) Multivariate Analysis and its Applications, New Central Book Agency Pvt Ltd., India.

22. Urmi AF, Bhuyan KC (2018) Identification of factors responsible for obesity in children and adolescents of some affluent families. BJSTR 10(5): 8121-8129.
This work is licensed under Creative Commons Attribution 4.0 License

To Submit Your Article Click Here: Submit Article

DOI: $10.32474 / A D 0.2019 .02 .000142$ 